\title{
Is a previous diagnosis of asthma a reliable criterion for asthma-COPD overlap syndrome in a patient with COPD?
}

This article was published in the following Dove Press journal:

International Journal of COPD

I September 2015

Number of times this article has been viewed

\author{
Miriam Barrecheguren' \\ Miguel Román-Rodríguez ${ }^{2}$ \\ Marc Miravitlles' \\ 'Pneumology Department, Hospital \\ Universitari Vall d'Hebron, Ciber \\ de Enfermedades Respiratorias \\ (CIBERES), Barcelona, ${ }^{2}$ Primary Health \\ Care Center Son Pisà, IB-Salut, Palma \\ de Mallorca, Spain
}

Background: Some patients share characteristics of both COPD and asthma. As yet, there is no gold standard to identify patients with the so-called asthma-COPD overlap syndrome (ACOS).

Objective: To describe the differences between ACOS patients and the remaining COPD patients, and to compare the clinical characteristics of patients diagnosed with ACOS by two different criteria: previous diagnosis of asthma before the age of 40 years; and the diagnostic criteria of the Spanish guidelines of COPD.

Methods: Multicenter, observational, cross-sectional study performed in 3,125 COPD patients recruited in primary care and specialized outpatient clinics. Patients with COPD and a history of asthma before the age of 40 years were diagnosed with ACOS and compared to the remaining COPD patients. Subsequently, ACOS patients were subdivided based on whether they fulfilled the Spanish guidelines of the COPD diagnostic criteria or not, and they were compared.

Results: ACOS was diagnosed in $15.9 \%$ of the patients. These patients had different basal characteristics compared to the remaining COPD patients, including a higher frequency of women and more exacerbations despite lower tobacco exposure and better lung function. They were more likely to have features of asthma, such as a positive bronchodilator test, higher peripheral eosinophilia, and higher total immunoglobulin E. Within the ACOS group, only one-third fulfilled the diagnostic criteria of the Spanish guidelines of COPD; these individuals were not significantly different from the remaining ACOS patients, except for having more exacerbations and poorer lung function.

Conclusion: ACOS patients diagnosed on the basis of a previous diagnosis of asthma differed from the remaining COPD patients, but they were similar to ACOS patients diagnosed according to more restrictive criteria, suggesting that a history of asthma before the age of 40 years could be a useful criterion to suspect ACOS in a patient with COPD.

Keywords: COPD, phenotypes, ACOS

\section{Introduction}

COPD is a very heterogeneous disease and, although all patients present with chronic non-fully reversible airflow limitations, the clinical presentation and prognosis may differ. ${ }^{1}$ In recent years, clinical phenotypes have been proposed to better classify patients with similar features, and particularly with a similar response to existing therapies. ${ }^{2,3}$ Among the phenotypes of COPD, the asthma-COPD overlap syndrome (ACOS), which shares some features with those of asthma, has attracted the most attention and research. ${ }^{4,5}$

Compared to other COPD individuals, patients with this phenotype have an increased reversibility of airflow obstruction and, more importantly, a higher degree of
Correspondence: Marc Miravitlles Pneumology Department, Hospital Universitari Vall d'Hebron, $P$ Vall d'Hebron II 9-I29, 08035

Barcelona, Spain

Tel +34932746083

Fax +34 932746083

Email mmiravitlles@vhebron.net 
eosinophilic bronchial inflammation, which may imply better response to therapy with inhaled corticosteroids (ICS).$^{6-8}$

With that purpose, some national guidelines have recognized this phenotype and have proposed criteria for its identification. In Spain, a group of experts proposed diagnostic criteria in a consensus document, ${ }^{9}$ and these were subsequently included in the Spanish guidelines of COPD (GesEPOC) for the diagnosis of ACOS. ${ }^{10}$ The latest Czech Republic guidelines $^{11}$ and the Finnish guidelines ${ }^{12}$ also included the ACOS with their own diagnostic criteria, and they were basically a modification of the previous Spanish guidelines.

However, the criteria proposed in these guidelines are quite restrictive and some of the variables included are not readily available in daily clinical practice in every center. Moreover, these criteria are based on expert opinion and have not been formally validated; therefore, recognition of ACOS patients might be difficult despite guideline recommendations. ${ }^{13}$ It has been suggested that the main feature of ACOS in COPD is a previous diagnosis of asthma before the age of 40 years, which has been used as a diagnostic criterion of ACOS in large epidemiologic studies, such as the COPDGene ${ }^{14}$ or EPI-SCAN,${ }^{15}$ although this has not been validated either.

In an attempt to compare the characteristics of patients with ACOS with the remaining COPD patients, and particularly to compare ACOS identified solely on the basis of previous diagnosis of asthma before the age of 40 years with ACOS diagnosed by the more restrictive criteria of the Spanish consensus, we analyzed the data of a large cohort of COPD patients from both primary care and specialized centers. The hypothesis was that ACOS patients with a previous diagnosis of asthma before the age of 40 years do not differ from those diagnosed with ACOS according to more restrictive criteria and, thus, the history of asthma before the age of 40 years could be used to identify patients likely to have ACOS from a COPD population.

\section{Methods}

\section{Study design}

We performed a multicenter, observational, cross-sectional study aimed at describing the prevalence and main characteristics of the clinical phenotypes of COPD. ${ }^{16}$ We compared the characteristics of patients diagnosed with ACOS based on a previous diagnosis of asthma with the remaining COPD patients. In a further analysis, we compared the characteristics of ACOS patients diagnosed according to the diagnostic criteria of GesEPOC with the remaining ACOS individuals diagnosed solely on the basis of a previous diagnosis of asthma.

\section{Patients}

The inclusion criteria were: patients $\geq 40$ years of age diagnosed with COPD in medical records; smokers or exsmokers of at least 10 pack-years; and a postbronchodilator forced expiratory volume in 1 second $\left(\mathrm{FEV}_{1}\right)$ /forced vital capacity ratio less than 0.7 . COPD diagnostic spirometry was performed at inclusion or during the previous 12 months. The exclusion criteria were: the presence of another severe chronic respiratory disease (cystic fibrosis, pulmonary fibrosis, active neoplasm); and the inability to read or understand the questionnaires used in the study.

COPD patients reporting a previous diagnosis of asthma before the age of 40 years were included in the ACOS group. Subsequently, ACOS patients were subdivided into two subgroups. ACOS 1: patients that fulfilled the ACOS diagnostic criteria of the Spanish consensus. ${ }^{9}$ These criteria were: 1) major criteria: very positive bronchodilator test (improvement in $\mathrm{FEV}_{1}>400 \mathrm{~mL}$ and $>15 \%$ ); sputum eosinophilia or a previous diagnosis of asthma before the age of 40 years. 2) Minor criteria: increased total serum immunoglobulin(Ig)E; and previous history of atopy or a positive bronchodilator test $\left(>200 \mathrm{~mL}\right.$ and $>12 \%$ in $\left.\mathrm{FEV}_{1}\right)$ on at least two occasions. To be included in this subgroup, a patient had to fulfill two major, or one major and two minor criteria. ACOS 2: the remaining patients with ACOS, diagnosed only on the basis of a history of asthma before the age of 40 years, but not fulfilling the diagnostic criteria of the Spanish consensus.

The study was approved by the Committee of Ethics and Clinical Investigation of the Hospital Clínic of Barcelona (number 2012/7962), and all the patients included provided written informed consent to participate in the study.

\section{Variables}

Each investigator filled out a remote data capture including sociodemographic and clinical variables. Dyspnea was graded according to the Modified Medical Research Council Dyspnea Scale. ${ }^{17}$ COPD severity was assessed by the Body Mass Index, Airflow Obstruction Dyspnea and Exacerbations (BODE) index ${ }^{18}$ and the COPD Severity Score (COPDSS) questionnaire developed by Eisner et $\mathrm{al}^{19}$ and translated and validated into Spanish. ${ }^{20}$ Comorbidities were analyzed using the Charlson et al index, ${ }^{21}$ and the level of physical activity by self-reported average daily time walked in the previous week, as in previous studies. ${ }^{22,23}$

Quality of life was assessed with the generic EuroQoL-5 dimensions (EQ-5D) and the specific COPD Assessment Test (CAT). The EQ-5D is a generic quality of life 
questionnaire consisting of two parts: the first part is a five-dimension health status description, the scores of which are grouped into an overall index ranging from 0 (worst possible health state) to 1 (perfect health); the second part is a visual analog scale of $10 \mathrm{~cm}$, in which the patients indicate their health from 0 (the worst possible) to 100 (the best possible). ${ }^{24}$ The CAT is a brief specific questionnaire designed to quantify the impact of COPD on the health status of the patient. It is based on eight items that are scored from 0 to 5 , with a total score of between 0 and 40 , in which a higher score indicates a greater impact of the disease on the patient. ${ }^{25}$

Psychological status was assessed using the Hospital Anxiety and Depression Scale (HADS), which has been validated to identify anxiety and depression cases in patients with chronic diseases. This questionnaire contains seven items for depression (depression subscale, or HAD-D) and seven for anxiety (anxiety subscale, or HAD-A). The score for each subscale ranges from 0 to 21 . A score from 0 to 7 indicates no anxiety or depression, while a score of between 8 and 10 is suggestive of the presence of a mood disorder, and a score of 11 or higher is indicative of the likely presence of anxiety or depression. ${ }^{26}$

Exacerbations in the previous year were obtained from medical records and the clinical interview with the patient at the inclusion visit. They were defined as episodes of an increase in respiratory symptoms that required treatment with either systemic corticosteroids, antibiotics, or both, or that required emergency visits or hospital admission.

\section{Statistical analysis}

A descriptive analysis of the sociodemographic characteristics of the whole population with COPD was made. First, a descriptive and comparative analysis of the ACOS and non-ACOS groups was performed, followed by a descriptive and comparative analysis of the ACOS patients divided into two subgroups according to the different diagnostic criteria used. Comparison of qualitative variables was performed using $\chi^{2}$ tests, and quantitative variables by Student's $t$-test if they had a normal distribution, or the Mann-Whitney $U$-test if the variables did not follow a normal distribution.

Comparisons among the scores of the CAT, EQ-5D, HADS, and COPDSS scales between ACOS 1 and 2 were evaluated by linear regression models and logistic regression models adjusted by $\mathrm{FEV}_{1}(\%)$ and the number of exacerbations in the previous year. All statistical analyses were performed using the $\mathrm{SAS}^{\circledR}$ statistical software system version 9.3
(SAS Institute Inc., Cary, NC, USA); values were considered significant with a bilateral $P<0.05$.

\section{Results \\ Patient population}

A total of 3,125 patients were recruited-1,974 (63.1\%) from primary care and 1,151 (36.9\%) from the pneumology department. The mean age of the population was 66.9 years (standard error of the mean [SEM]: 0.2); 82.4\% were male and the mean $\mathrm{FEV}_{1}$ (\%) was 53\% (SEM: $0.3 \%$ ). The mean number of exacerbations during the previous year was 1.8 (SEM: 0.3) and the mean BODEx score was 2.9 (SEM: 0.04).

A total of 496 (15.9\%) patients with COPD and a previous history of asthma before the age of 40 years were included in the ACOS group. Of these patients, 158 (31.8\% of the ACOS group and $3.6 \%$ of the total COPD population) were included in the ACOS 1 group, while the remaining 338 (68.2\% of ACOS) made up the ACOS 2 group (Figure 1).

\section{Comparison between ACOS and non- ACOS patients}

Patients with ACOS were younger and more frequently female than the remaining COPD patients. They smoked less and had better lung function, although no differences were observed regarding symptoms. The BODEx index was lower in patients with ACOS (Table 1).

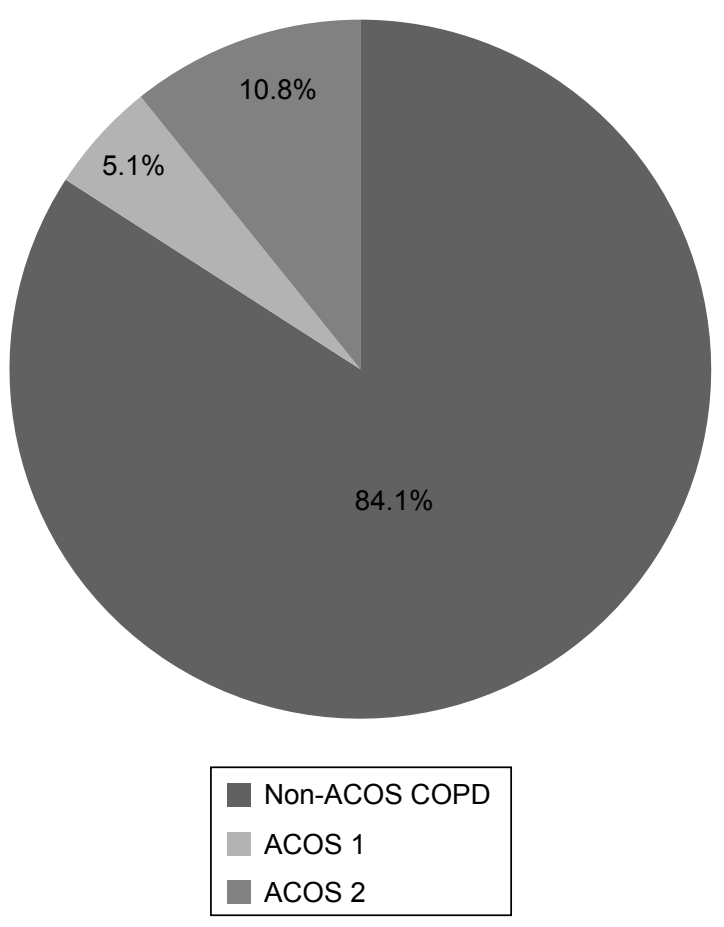

Figure I Distribution of non-ACOS and ACOS patients. Abbreviation: ACOS, asthma-COPD overlap syndrome. 
Table I Baseline characteristics of patients with ACOS defined as COPD with a previous diagnosis of asthma before the age of 40 years versus non-ACOS patients

\begin{tabular}{|c|c|c|c|c|}
\hline Variable & $\begin{array}{l}\text { Non-ACOS } \\
(n=2,629)\end{array}$ & $\begin{array}{l}\text { ACOS } \\
(n=496)\end{array}$ & $\begin{array}{l}\text { Total } \\
(n=3,125)\end{array}$ & $P$-value \\
\hline Sex (men) & $2,229(84.8 \%)$ & $346(69.8 \%)$ & $2,575(82.4 \%)$ & $<0.001$ \\
\hline Age (years) & $67.4(0.2)$ & $64.6(0.4)$ & $66.9(0.2)$ & $<0.001$ \\
\hline BMI $\left(\mathrm{kg} / \mathrm{m}^{2}\right)$ & $27.7(0.1)$ & $28.3(0.2)$ & $27.8(0.1)$ & 0.003 \\
\hline Active smoker & $601(22.9 \%)$ & $125(25.2 \%)$ & $726(23.2 \%)$ & 0.082 \\
\hline Pack-years & $41.3(0.5)$ & $32.3(1.2)$ & $40.1(0.5)$ & $<0.001$ \\
\hline Time walked per day, minutes & $63.3(2.1)$ & $66.1(2.12)$ & $63.7(2.0)$ & 0.36 \\
\hline \multicolumn{5}{|l|}{ Spirometry (postbronchodilator) } \\
\hline $\mathrm{FVC}(\mathrm{L})$ & $2.8(0.02)$ & $3.02(0.04)$ & $2.9(0.02)$ & 0.0001 \\
\hline FVC\% & $68.7(0.4)$ & $75.2(0.9)$ & $69.7(0.4)$ & $<0.001$ \\
\hline $\mathrm{FEV}_{1}(\mathrm{~L})$ & $1.5(0.01)$ & $1.7(0.03)$ & $1.6(0.01)$ & $<0.001$ \\
\hline $\mathrm{FEV}_{1} \%$ & $51.9(0.4)$ & $59.4(1.0)$ & $53.0(0.3)$ & $<0.001$ \\
\hline $\mathrm{FEV}_{1} / \mathrm{FVC}$ & $53.4(0.2)$ & $55.3(0.6)$ & $53.7(0.2)$ & $<0.001$ \\
\hline \multicolumn{5}{|l|}{ Symptoms } \\
\hline mMRC, mean (SD) & $\mathrm{I} .7(0.02)$ & $\mathrm{I} .7(0.04)$ & $\mathrm{I} .7(0.02)$ & 0.31 \\
\hline Chronic cough & $1,939(73.8 \%)$ & $389(78.4 \%)$ & $2,328(74.5 \%)$ & 0.07 \\
\hline Daily expectoration & $1,650(62.8 \%)$ & $325(65.5 \%)$ & $1,975(63.2 \%)$ & 0.38 \\
\hline BODEx index & $2.9(0.04)$ & $2.5(0.08)$ & $2.9(0.04)$ & $<0.001$ \\
\hline Charlson Comorbidity Index & $1.4(0.06)$ & $1.4(0.07)$ & $1.4(0.07)$ & 0.82 \\
\hline Positive bronchodilator test $\left(\mathrm{FEV}_{1}>12 \%,>200 \mathrm{~mL}\right)$ & $99(3.9 \%)$ & $56(11.3 \%)$ & $155(5.0 \%)$ & $<0.001$ \\
\hline Very positive bronchodilator test* (FEV $>15 \%,>400 \mathrm{~mL}$ ) & $231(8.9 \%)$ & $140(22.2 \%)$ & $371(11.9 \%)$ & $<0.001$ \\
\hline \% blood eosinophilic count (mean, SEM) & $2.9(0.2)$ & $4.8(0.4)$ & $3.4(0.2)$ & $<0.001$ \\
\hline Clinical/radiologic signs of emphysema & 1,035 (39.4\%) & $161(32.5 \%)$ & $1,196(38.3 \%)$ & 0.007 \\
\hline Number of exacerbations in the previous 12 months & $1.8(0.03)$ & $2.0(0.07)$ & $1.8(0.03)$ & 0.0006 \\
\hline Hospital admissions in the previous 2 years & $1.0(0.03)$ & $1.2(0.08)$ & $1.0(0.03)$ & 0.03 \\
\hline
\end{tabular}

Notes: Data are shown as the mean (SEM) unless otherwise specified. *Very positive bronchodilator test recorded at any time during the previous year, while positive bronchodilator test refers to the inclusion spirometry.

Abbreviations: ACOS, asthma-COPD overlap syndrome; $n$, number; BMI, body mass index; FVC, forced vital capacity; FEV , forced expiratory volume in I second; mMRC, modified Medical Research Council Dyspnea Scale; SD, standard deviation; BODEx, Body Mass Index, Airflow Obstruction, Dyspnea and Exacerbations; SEM, standard error of the mean.

Patients with ACOS more frequently presented with a positive and very positive bronchodilator test, more peripheral eosinophilia, a higher total IgE, and more exacerbations and hospitalizations compared to the remaining COPD patients. In contrast, they less frequently had clinical or radiological signs of emphysema.

The scores obtained with the Health-Related Quality of Life (HRQL) questionnaires were similar in both groups, but patients with ACOS more frequently had scores $\geq 8$, suggesting anxiety and depression (34.9\% and $36.6 \%$ versus $27.6 \%$ and $29.2 \%$, respectively; $P=0.0011$ ) (Table 2 ).

\section{Comparison between the two populations of patients with ACOS}

There were no significant differences in the demographic characteristics between the two groups of patients with ACOS

Table 2 Severity of COPD, quality of life, anxiety, and depression in patients with ACOS defined as COPD with a previous diagnosis of asthma before the age of 40 years versus non-ACOS patients

\begin{tabular}{lllll}
\hline Variable & Non-ACOS (n=2,629) & ACOS (n=496) & Total (n=3, I 25) & P-value \\
\hline COPDSS & $10.4(0.1)$ & $10.3(0.2)$ & $10.4(0.1)$ & 0.66 \\
CAT & $19.2(0.2)$ & $19.6(0.4)$ & $19.3(0.1)$ & 0.43 \\
EQ-5D index & $0.65(0.01)$ & $0.62(0.01)$ & $0.65(0.01)$ & 0.03 \\
EQ-5D VAS & $57.7(0.4)$ & $57.4(0.8)$ & $57.6(0.3)$ & 0.79 \\
Anxiety (HADS) & $7.7(0.1)$ & $8.7(0.2)$ & $7.8(0.1)$ & $<0.001$ \\
Probable anxiety ( $\geq 8$ points) & $27.6 \%$ & $34.9 \%$ & $28.8 \%$ & 0.0011 \\
Depression (HADS) & $7.7(0.1)$ & $8.2(0.2)$ & $7.8(0.1)$ & 0.007 \\
Probable depression ( $\geq 8$ points) & $29.2 \%$ & $36.6 \%$ & $30.4 \%$ & 0.0011 \\
\hline
\end{tabular}

Note: Data are shown as the mean (SEM) unless otherwise specified.

Abbreviations: ACOS, asthma-COPD overlap syndrome; n, number; COPDSS, COPD Severity Score; CAT, COPD Assessment Test; EQ-5D, EuroQoL-5 dimensions; VAS, visual analog scale; HADS, Hospital Anxiety and Depression Scale; SEM, standard error of the mean. 
Table 3 Baseline characteristics of patients with an ACOS I phenotype defined as patients with COPD fulfilling the Spanish consensus criteria for ACOS, and ACOS 2 defined as COPD with only a previous diagnosis of asthma before the age of 40 years

\begin{tabular}{|c|c|c|c|}
\hline Variable & $A \cos I(n=158)$ & $A \cos 2(n=338)$ & $P$-value \\
\hline Sex (men) & $113(71.5 \%)$ & $233(68.9 \%)$ & 0.56 \\
\hline Age (years) & $63.4(0.7)$ & $65.1(0.5)$ & 0.06 \\
\hline $\mathrm{BMI}\left(\mathrm{kg} / \mathrm{m}^{2}\right)$ & $28.7(0.3)$ & $28.2(0.2)$ & 0.22 \\
\hline Active smoker & $42(26.6 \%)$ & $83(26.9 \%)$ & 0.59 \\
\hline Pack-years & $33.4(1.9)$ & $31.9(1.4)$ & 0.006 \\
\hline Time walked per day, minutes & $65.7(2.1)$ & $66.3(2.0)$ & 0.62 \\
\hline \multicolumn{4}{|l|}{ Spirometry, postbronchodilator } \\
\hline FVC (L) & $3.1(0.07)$ & $3.0(0.05)$ & 0.53 \\
\hline FVC\% & $76.3(1.6)$ & $74.8(1.1)$ & 0.43 \\
\hline $\mathrm{FEV}_{1}(\mathrm{~L})$ & $1.8(0.05)$ & $1.7(0.04)$ & 0.02 \\
\hline $\mathrm{FEV}_{1} \%$ & $63.0(1.6)$ & $57.8(1.2)$ & 0.012 \\
\hline $\mathrm{FEV}_{1} / \mathrm{FVC}$ & $56.1(1.1)$ & $54.9(0.6)$ & 0.09 \\
\hline \multicolumn{4}{|l|}{ Symptoms } \\
\hline mMRC, mean (SD) & $1.7(0.07)$ & $1.6(0.05)$ & 0.07 \\
\hline Chronic cough & $130(82.3 \%)$ & $259(76.6 \%)$ & 0.33 \\
\hline Daily expectoration & $113(71.5 \%)$ & $212(62.7 \%)$ & 0.08 \\
\hline BODEx index, mean (SD) & $2.5(0.1)$ & $2.5(0.1)$ & 0.62 \\
\hline Charlson Comorbidity Index & $1.6(0.07)$ & $1.3(0.06)$ & 0.005 \\
\hline \% blood eosinophilic count (mean, SD) & $4.9(0.5)$ & $4.7(0.6)$ & 0.14 \\
\hline Number of exacerbations in the previous 12 months & $2.3(0.1)$ & $1.9(0.1)$ & 0.006 \\
\hline Hospital admissions in the previous 2 years & $1.2(0.1)$ & I.I (0.I) & 0.39 \\
\hline
\end{tabular}

Note: Data are shown as the mean (SEM) unless otherwise specified.

Abbreviations: ACOS, asthma-COPD overlap syndrome; $\mathrm{n}$, number; BMI, body mass index; FVC, forced vital capacity; $\mathrm{FEV}_{1}$, forced expiratory volume in I second; mMRC, Modified Medical Research Council Dyspnea Scale; SD, standard deviation; BODEx, Body Mass Index, Airflow Obstruction, Dyspnea and Exacerbations; SEM, standard error of the mean.

(Table 3). With regard to COPD characteristics, patients in the ACOS 1 group had a higher $\mathrm{FEV}_{1} \%$ (63\% [SEM: 1.6] versus $57.8 \%$ [SEM: 1.2$] ; P=0.012$ ). The symptoms were similar in both groups, and only dyspnea was more frequent and severe in the ACOS 1 group. The percentage of patients with peripheral or sputum eosinophilia was similar between groups.

The HRQL score, the level of physical activity, and the anxiety and depression scores showed no significant differences between the two groups (Table 4).

\section{Discussion}

Patients with ACOS, defined as COPD with a previous diagnosis of asthma before the age of 40 years, represented $15.9 \%$ of our large cohort of patients recruited in both primary care and specialized respiratory clinics. Patients with this phenotype had different demographic and clinical characteristics compared to the remaining COPD patients, including a higher frequency of women and more frequent exacerbations, despite having lower tobacco exposure and

Table 4 Severity of COPD, quality of life, anxiety, and depression in the ACOS I group, defined as patients with COPD fulfilling the Spanish consensus criteria for ACOS, and the ACOS 2 group, defined as COPD with only a previous diagnosis of asthma before the age of 40 years

\begin{tabular}{|c|c|c|c|}
\hline Variable & $\operatorname{ACOS} I(n=\mid 58)$ & $\operatorname{ACOS} 2(n=338)$ & $P$-value \\
\hline COPDSS & $9.7(0.4)$ & $10.5(0.3)$ & 0.07 \\
\hline CAT & $19.6(0.6)$ & $19.5(0.4)$ & 0.89 \\
\hline EQ-5D index & $0.61(0.03)$ & $0.62(0.02)$ & 0.71 \\
\hline EQ-5D VAS & $56.0(1.4)$ & $57.7(1.0)$ & 0.33 \\
\hline HADS & I 7.07 (0.7) & $16.8(0.5)$ & 0.83 \\
\hline Anxiety (HADS) & $8.7(0.4)$ & $8.7(0.2)$ & 0.90 \\
\hline Probable anxiety ( $\geq 8$ points) & $30.9 \%$ & $34.5 \%$ & 0.46 \\
\hline Depression (HADS) & $8.4(0.4)$ & $8.2(0.3)$ & 0.68 \\
\hline Probable depression ( $\geq 8$ points) & $37.3 \%$ & $36.0 \%$ & 0.79 \\
\hline
\end{tabular}

Notes: $P$-values for comparisons have been calculated using linear regression models and logistic regression models. The variables $\mathrm{FEV}$, and number of exacerbations have been included for adjustment. Data are shown as the mean (SEM) unless otherwise specified. $P$-values were obtained by linear regression models and logistic regression models adjusted by $\mathrm{FEV}_{1}(\%)$ and number of exacerbations in the previous year.

Abbreviations: ACOS, asthma-COPD overlap syndrome; n, number; COPDSS, COPD Severity Score; CAT, COPD Assessment Test; EQ-5D, EuroQoL-5 dimensions; VAS, visual analog scale; HADS, Hospital Anxiety and Depression Scale; SEM, standard error of the mean. 
better lung function. They were more likely to have features of asthma, such as a positive and very positive bronchodilator test, peripheral eosinophilia, and a higher total IgE. Among the ACOS group, only one-third fulfilled the diagnostic criteria of the Spanish guidelines of COPD, but interestingly, these individuals were mostly similar to the remaining ACOS patients.

Large epidemiological studies in the USA and Spain have defined ACOS as COPD individuals with a previous diagnosis of asthma before the age of 40 years, and they have described frequencies of ACOS of $13 \%$ and $17 \%$, respectively. ${ }^{14,15}$ Using this criterion in our COPD patient population, $15.9 \%$ had a previous history of asthma before the age of 40 years, and they were defined as ACOS. In patients with alpha-1 antitrypsin deficiency and lung disease from the Italian and Spanish registries, the prevalence of ACOS by the same criterion was lower $(8.6 \%)$, but with similar characteristics to ACOS in patients with COPD not related to alpha-1. ${ }^{27}$ On comparing ACOS patients identified with this definition among the remaining COPD individuals, the ACOS patients are usually younger, more frequently female, with better lung function but poorer health status, more exacerbations, and they have had lower smoking exposure compared to non-ACOS patients, ${ }^{14,15,27,28}$ which is in agreement with our results. The ACOS population presented in this study was more likely to have a positive or very positive bronchodilator test, peripheral eosinophilia, or a higher total IgE; all characteristics were also presented by asthma patients and considered suggestive of ACOS. ${ }^{13}$ However, there were no differences in the severity of respiratory symptoms and impairment in quality of life, but the severity of the disease measured by the BODEx index was milder in the ACOS group. The HADS suggested a higher prevalence of both comorbidities in the ACOS group.

There are still no universally accepted diagnostic criteria for ACOS. The recent Global Initiative for Asthma (GINA)-Global Initiative for Chronic Obstructive Lung Disease (GOLD) joint committee document defines ACOS as a syndrome characterized by persistent airflow limitation with several features usually associated with asthma and several features usually associated with COPD. To identify an ACOS patient, a physician must consider characteristics favoring a diagnosis of asthma or COPD based on the patient's clinical history, compare the number of features indicating a diagnosis of either asthma or COPD, and finally determine whether there are features of both suggesting ACOS. ${ }^{29}$ Izquierdo-Alonso et $\mathrm{al}^{30}$ suggested that a previous diagnosis of asthma before the age of 40 years, plus no signs of emphysema by imaging techniques, and a $\mathrm{CO}$ diffusion capacity greater than $80 \%$ were predicted as criteria for ACOS in COPD, and they identified $12.1 \%$ of ACOS patients in a group of 322 COPD subjects. Other guidelines such as those of the Czech Republic ${ }^{11}$ and the Finnish ${ }^{12}$ and Spanish guidelines of COPD ${ }^{10}$ have defined their own diagnostic criteria for ACOS. According to the latter guidelines, to be diagnosed with ACOS, a COPD patient must fulfill some characteristics, with at least one being a very positive bronchodilator response, sputum eosinophilia, or a previous diagnosis of asthma. With these criteria, only approximately one-third of patients with a previous diagnosis of asthma before 40 years of age would be diagnosed with ACOS, representing only $3.6 \%$ of the whole population. Similar results have been observed in previous series of unselected patients with COPD; Golpe et $\mathrm{al}^{31}$ found only $5 \%$ of patients with ACOS in a population of 499 COPD individuals, and Miravitlles et $\mathrm{al}^{32}$ identified $6.5 \%$ of subjects with ACOS among 346 patients with COPD. These percentages are very low and clearly below the estimated incidence of ACOS according to the prevalence of asthma and COPD reflected in the GINA-GOLD document. ${ }^{29}$ Furthermore, some of these criteria require diagnostic techniques not readily available by every practicing physician.

Since, as yet, there is no gold standard for the diagnosis of ACOS, it would be useful to demonstrate if individuals diagnosed with ACOS with the more stringent criteria defined in national guidelines have the same or similar characteristics to those individuals with ACOS identified in large epidemiological studies based on the previous diagnosis of asthma alone. If the demographic and clinical characteristics of patients diagnosed by the two sets of criteria are similar, a previous diagnosis of asthma before the age of 40 years in a patient with diagnosed COPD could be a very simple and accurate diagnostic criterion until new studies more precisely define the characteristics of ACOS and provide a gold standard for diagnosis. ${ }^{13}$

When we compared patients fulfilling the Spanish consensus criteria with the remaining ACOS patients, there were no significant differences regarding demographic characteristics. Only $\mathrm{FEV}_{1}$ (\% predicted) was lower, and exacerbations during the previous year were more frequent in patients with ACOS according to the more restrictive criteria of the Spanish consensus. However, no other clinical differences were observed, and neither were differences in HRQL, severity indices, or anxiety and depression. These results suggest that a previous diagnosis of asthma before the age of 40 years by itself may be useful to identify patients with ACOS among the general COPD population. 
The GINA-GOLD document describes a very variable prevalence of ACOS ranging from 5\% to 55\%. ${ }^{29}$ However, the studies with the highest prevalence are database studies that diagnose ACOS in any patient with both diagnoses (COPD and asthma) registered in the clinical records at any time, ${ }^{13,33}$ probably overestimating the real prevalence of ACOS. This is due to the presence of older or more severe COPD patients who are more likely to have ever been diagnosed with asthma (correctly or not) according to what was registered in their medical records at some time during their lives. ${ }^{33,34}$

In the search for new diagnostic tools, it has been suggested that biomarkers could help to identify ACOS patients. Along this line, increased sputum levels of neutrophil gelatinase-associated lipocalin have been described as a characteristic feature of overlap in contrast with COPD or asthma alone. ${ }^{35}$ The presence of bronchial eosinophilic inflammation is also suggestive of ACOS and it is indicative of a better response to ICS in COPD. ${ }^{36,37}$ Despite being one of the major diagnostic criteria of ACOS in the Spanish consensus, ${ }^{9}$ sputum eosinophilia is rarely available and eosinophil counts in sputum were only reported in $1 \%$ of our patients. Recent studies have suggested that blood eosinophil concentrations, which are more accessible than sputum eosinophils, could be used as a biomarker of response to treatment with oral ${ }^{38}$ and ICS ${ }^{39}$ in COPD. From the perspective of clinicians, the importance of ACOS is to identify a subgroup of patients with COPD with impaired HRQL and an increased risk of exacerbations despite better preserved lung function, particularly because ACOS responds better to ICS. ${ }^{40}$ If future studies demonstrate that blood eosinophils are a reliable marker of response to ICS in COPD, interest in ACOS from a clinical point of view may be replaced by interest in "eosinophilic COPD".

Our study has some limitations. Since there is a lack of a gold standard for the diagnosis of ACOS, we cannot confirm that all the patients identified would be diagnosed with ACOS by other criteria. The sample of patients included may not be fully representative of all patients with COPD in Spain; however, we recruited a large sample of patients both in primary and secondary care with very limited exclusion criteria. Finally, women were underrepresented, but this reflects the epidemiology of COPD in Spain where approximately twothirds of COPD patients are male. ${ }^{41}$

\section{Conclusion}

In conclusion, patients diagnosed with ACOS in COPD on the basis of a previous diagnosis of asthma before the age of 40 years are very similar to patients diagnosed with ACOS by the more restrictive criteria proposed by the Spanish consensus. Therefore, the previous diagnosis of asthma before 40 years of age in a patient with COPD can be used as a presumptive diagnosis of ACOS. This conclusion is supported by the data, which show that globally, patients with ACOS diagnosed on the basis of a previous diagnosis of asthma in COPD have different characteristics compared with the remaining COPD patients, and that patients with ACOS diagnosed by the Spanish criteria have similar characteristics compared with the remaining ACOS patients.

\section{Acknowledgments}

Funding was provided by Laboratorios Esteve S.A. (Barcelona, Spain). The authors are deeply grateful to all the physicians who participated in this study and provided invaluable data. We would also like to thank Jordi Cantoni and Josep Puig (Bioclever 2005 S.L., Barcelona, Spain) for their support in the logistics and statistical analysis of the data.

\section{Disclosure}

Marc Miravitlles has received speaker fees from Boehringer Ingelheim, Pfizer, AstraZeneca, Novartis, Grifols, Takeda and Novartis; he has received honoraria from Laboratorios Esteve S.A. (Barcelona, Spain) for the design and development of the current study; and he also has received consulting fees from Boehringer Ingelheim, Pfizer, GlaxoSmithKline, AstraZeneca, Novartis, Almirall, Grifols, and Takeda. Miguel Román-Rodríguez has received speaker fees from Almirall, AstraZeneca, Boehringer Ingelheim, GlaxoSmithKline, Mundipharma, and Novartis. Miriam Barrecheguren reports no conflicts of interest in this work.

\section{References}

1. Decramer M, Janssens W, Miravitlles M. Chronic obstructive pulmonary disease. Lancet. 2012;379(9823):1341-1351.

2. Han MK, Agusti A, Calverley PM, et al. Chronic obstructive pulmonary disease phenotypes: the future of COPD. Am J Respir Crit Care Med. 2010; 182(5):598-604.

3. Miravitlles M, Calle M, Soler-Cataluña JJ. Clinical phenotypes of COPD: identification, definition and implications for guidelines. Arch Bronconeumol. 2012;48(3):86-98.

4. Gibson PG, Simpson JL. The overlap syndrome of asthma and COPD: what are its features and how important is it? Thorax. 2009;64(8): 728-735.

5. Piras B, Miravitlles M. The overlap phenotype: the (missing) link between asthma and COPD. Multidiscip Respir Med. 2012;7(1):8.

6. Disantostefano RL, Li H, Rubin DB, Stempel DA. Which patients with chronic obstructive pulmonary disease benefit from the addition of an inhaled corticosteroid to their bronchodilator? A cluster analysis. BMJ Open. 2013;3(4). pii: e001838.

7. Kitaguchi Y, Komatsu Y, Fujimoto K, Hanaoka M, Kubo K. Sputum eosinophilia can predict responsiveness to inhaled corticosteroid treatment in patients with overlap syndrome of COPD and asthma. Int J Chron Obstruct Pulmon Dis. 2012;7:283-289. 
8. Louie S, Zeki AA, Schivo M, et al. The asthma-chronic obstructive pulmonary disease overlap syndrome: pharmacotherapeutic considerations. Expert Rev Clin Pharmacol. 2013;6(2):197-219.

9. Soler-Cataluña JJ, Cosío B, Izquierdo JL, et al. Consensus document on the overlap phenotype COPD-asthma in COPD. Arch Bronconeumol. 2012; 48(9):331-337.

10. Miravitlles M, Soler-Cataluña JJ, Calle M, et al. Spanish guideline for COPD (GesEPOC). Update 2014. Arch Bronconeumol. 2014;50 Suppl 1: $1-16$.

11. Koblizek V, Chlumsky J, Zindr V, et al; Czech Pneumological and Phthisiological Society. Chronic Obstructive Pulmonary Disease: official diagnosis and treatment guidelines of the Czech Pneumological and Phthisiological Society; a novel phenotypic approach to COPD with patient-oriented care. Biomed Pap Med Fac Univ Palacky Olomouc Czech Repub. 2013;157(2):189-201.

12. Kankaanranta H, Harju T, Kilpeläinen M, et al. Diagnosis and pharmacotherapy of stable chronic obstructive pulmonary disease: the Finnish guidelines. Basic Clin Pharmacol Toxicol. 2015;116(4):291-307.

13. Barrecheguren M, Esquinas C, Miravitlles M. The asthma-chronic obstructive pulmonary disease overlap syndrome (ACOS): opportunities and challenges. Curr Opin Pulm Med. 2015;21(1):74-79.

14. Hardin M, Silverman EK, Barr RG, et al; COPDGene Investigators. The clinical features of the overlap between COPD and asthma. Respir Res. 2011;12:127.

15. Miravitlles M, Soriano JB, Ancochea J, et al. Characterisation of the overlap COPD-asthma phenotype. Focus on physical activity and health status. Respir Med. 2013;107(7):1053-1060.

16. Miravitlles M, Barrecheguren M, Roman-Rodríguez M. Frequency and characteristics of different clinical phenotypes of COPD. The International Journal of Tuberculosis and Lung Disease. 2015;19(8): 992-998.

17. Bestall JC, Paul EA, Garrod R, Garnham R, Jones PW, Wedzicha JA. Usefulness of the Medical Research Council (MRC) dyspnoea scale as a measure of disability in patients with chronic obstructive pulmonary disease. Thorax. 1999;54(7):581-586.

18. Soler-Cataluña JJ, Martínez-García MA, Sánchez LS, Tordera MP, Sánchez PR. Severe exacerbations and BODE index: two independent risk factors for death in male COPD patients. Respir Med. 2009; 103(5):692-699

19. Eisner MD, Trupin L, Katz PP, et al. Development and validation of a survey-based COPD severity score. Chest. 2005;127(6): 1890-1897.

20. Miravitlles M, Llor C, de Castellar R, Izquierdo I, Baró E, Donado E. Validation of the COPD severity score for use in primary care: the NEREA study. Eur Respir J. 2009;33(3):519-527.

21. Charlson ME, Pompei P, Ales KL, MacKenzie CR. A new method of classifying prognostic comorbidity in longitudinal studies: development and validation. J Chronic Dis. 1987;40(5):373-383.

22. Esteban C, Quintana JM, Aburto M, et al. Impact of changes in physical activity on health-related quality of life among patients with COPD. Eur Respir J. 2010;36(2):292-300.

23. Miravitlles M, Cantoni J, Naberan K. Factors associated with a low level of physical activity in patients with chronic obstructive pulmonary disease. Lung. 2014;192(2):259-265.

24. Badia X, Roset M, Montserrat S, Herdman M, Sequra A. [The Spanish version of EuroQol: a description and its applications. European Quality of Life scale]. Med Clin (Barc). 1999;112 Suppl 1:79-85.

International Journal of COPD

\section{Publish your work in this journal}

The International Journal of COPD is an international, peer-reviewed journal of therapeutics and pharmacology focusing on concise rapid reporting of clinical studies and reviews in COPD. Special focus is given to the pathophysiological processes underlying the disease, intervention programs, patient focused education, and self management protocols.
25. Jones PW, Harding G, Berry P, Wiklund I, Chen WH, Kline Leidy N. Development and first validation of the COPD Assessment Test. Eur Respir J. 2009;34(3):648-654.

26. Herrero MJ, Blanch J, Peri JM, De Pablo J, Pintor L, Bulbena A. A validation study of the hospital anxiety and depression scale (HADS) in a Spanish population. Gen Hosp Psychiatry. 2003;25(4):277-283.

27. Menezes AM, Montes de Oca M, Pérez-Padilla R, et al; PLATINO Team. Increased risk of exacerbation and hospitalization in subjects with an overlap phenotype: COPD-asthma. Chest. 2014;145(2):297-304.

28. Piras B, Ferrarotti I, Lara B, et al. Clinical phenotypes of Italian and Spanish patients with $\alpha 1$-antitrypsin deficiency. Eur Respir J. 2013;42(1):54-64.

29. GINA and Global Initiative for Chronic Obstructive Lung Disease (GOLD) [webpage on the Internet]. Asthma, COPD, and asthma-COPD overlap syndrome. GINA and Global Initiative for Chronic Obstructive Lung Disease; 2015. Available from: http://www.goldcopd.org/ asthma-copd-overlap.html. Accessed March 10, 2015.

30. Izquierdo-Alonso JL, Rodriguez-Gonzálezmoro JM, de Lucas-Ramos P, et al. Prevalence and characteristics of three clinical phenotypes of chronic obstructive pulmonary disease (COPD). Respir Med. 2013; 107(5):724-731.

31. Golpe R, Sanjuán López P, Cano Jiménez E, Castro Añón O, Pérez de Llano LA. Distribution of clinical phenotypes in patients with chronic obstructive pulmonary disease caused by biomass and tobacco smoke. Arch Bronconeumol. 2014;50(8):318-324.

32. Miravitlles M, Huerta A, Fernández-Villar JA, et al. Generic utilities in chronic obstructive pulmonary disease patients stratified according to different staging systems. Health Qual Life Outcomes. 2014;12:120.

33. Rhee CK, Yoon HK, Yoo KH, et al. Medical utilization and cost in patients with overlap syndrome of chronic obstructive pulmonary disease and asthma. COPD. 2014;11(2):163-170.

34. Pleasants RA, Ohar JA, Croft JB, et al. Chronic obstructive pulmonary disease and asthma-patient characteristics and health impairment. COPD. 2014;11(3):256-266.

35. Iwamoto H, Gao J, Koskela J, et al. Differences in plasma and sputum biomarkers between COPD and COPD-asthma overlap. Eur Respir J. 2014; 43(2):421-429

36. Brightling CE, McKenna S, Hargadon B, et al. Sputum eosinophilia and the short term response to inhaled mometasone in chronic obstructive pulmonary disease. Thorax. 2005;60(3):193-198.

37. Siva R, Green RH, Brightling CE, et al. Eosinophilic airway inflammation and exacerbations of COPD: a randomised controlled trial. Eur Respir J. 2007;29(5):906-913.

38. Bafadhel M, McKenna S, Terry S, et al. Blood eosinophils to direct corticosteroid treatment of exacerbations of chronic obstructive pulmonary disease: a randomized placebo-controlled trial. Am J Respir Crit Care Med. 2012;186(1):48-55.

39. Pascoe S, Locantore N, Dransfield M, Barnes NC, Pavord DI. Blood eosinophil counts, exacerbations, and response to the addition of inhaled fluticasone furoate to vilanterol in patients with chronic obstructive pulmonary disease: a secondary analysis of data from two parallel randomised controlled trials. Lancet Respir Med. 2015;3(6):435-422.

40. Miravitlles M, Soler-Cataluña JJ, Calle M, Soriano JB. Treatment of COPD by clinical phenotypes: putting old evidence into clinical practice. Eur Respir J. 2013;41(6):1252-1256.

41. Miravitlles M, Soriano JB, García-Río F, et al. Prevalence of COPD in Spain: impact of undiagnosed COPD on quality of life and daily life activities. Thorax. 2009;64(10):863-868.

This journal is indexed on PubMed Central, MedLine and CAS. The manuscript management system is completely online and includes a very quick and fair peer-review system, which is all easy to use. Visit http://www.dovepress.com/testimonials.php to read real quotes from published authors. 